\title{
Fibrous Material Science: Extensive and Persistent
}

\author{
Martin J. D. Clift \\ In Vitro Toxicology Group, Institute of Life Sciences, Centre for NanoHealth, Swansea University Medical School, \\ Singleton Park Campus, Swansea University, Swansea, Wales SA2 8PP, UK; m.j.d.clift@swansea.ac.uk; \\ Tel.: +44-179-260-2742 \\ Received: 7 February 2020; Accepted: 13 February 2020; Published: 18 February 2020 \\ check for \\ updates
}

It is my absolute pleasure to take up the position of Editor-in-Chief (EiC) of Fibers. In fact, I have been conducting the position since the summer of 2018 when my esteemed colleague, Prof. Stephen C. Bondy, stepped down after a highly successful period in which he oversaw the concept, application and very first publications of the journal at the start of his six-year tenure. In fact, since the origin of the journal in 2012, Fibers has published 364 articles (including original research articles, reviews, perspectives and editorials) either as standalone pieces or as part of any number of Special Issues (a total of 53 from 2012 to 2018). Professor Bondy further reviewed, in collaboration with the constantly helpful Editorial Office, the population of the Editorial Board. It was at this point in time that I joined the journal. In fact, it was my very first editorial board position as an academic. However, it is important to note that, at this time, that under the direction of Prof. Bondy, Fibers truly became a recognized journal within the fiber community. Furthermore, this has made for a seamless change in the stewardship of the journal.

Upon taking up my position as the new EiC in June 2018, it was my brief to further advance the journal beyond its current status. Notably, following discussions with the Editorial Office, we decided that it was important to make Fibers a noted journal within the many disciplines that it covers (e.g., engineering, physics, chemistry, biology, medicine). To achieve this, an initial attempt to obtain an SCIE ranking has already been submitted. Furthermore, in this period, an additional 179 articles have been published, in association with multiple other Special Issues. It has also been the focus of the editorial office and myself to focus on the next generation of fiber-based researchers, with two prestigious travel bursaries being awarded to high-caliber, up-and-coming researchers within the field of fiber research (in both 2019 and 2020). Another aim has been to promote key research via the Editor's Choice Articles, in addition to those which receive the most attention (via cites and views). Marketing of the journal is also taking center stage, with Editorial Board members consistently highlighting the validity of the journal throughout the fiber community and beyond. It is also prudent to note to all Editorial Board members that their role in assisting submissions (of their own research) helps to progress the journal.

In the context of the latter, research into the area of fibers continues to grow exponentially, as highlighted by the yearly figures. Reasons for such growth in this research area can be placed upon the extensive attributes of fibers, and how they can be manipulated to create special applications and develop our understanding of their physical and chemical processes. Moreover, the persistent nature of fiber research, from a biological perspective, sees greater focus being placed upon the human health implications of exposure to fibers from occupational to application-based scenarios. 
Thus, it can be considered that, as a journal, Fibers has become extensive in its reach within the field, as well as in its output since its inception in 2012. It is now the time, and our objective, to continue in the approaches already adopted in order to continue the persistent success of the journal!

(C) 2020 by the author. Licensee MDPI, Basel, Switzerland. This article is an open access article distributed under the terms and conditions of the Creative Commons Attribution (CC BY) license (http://creativecommons.org/licenses/by/4.0/). 